\title{
RESEARCH ON TEMPORAL AND SPATIAL VARIATION OF HEAT ISLAND EFFECT IN XI'AN, CHINA
}

\author{
GAO, Y. ${ }^{1}-$ CHANG, M. ${ }^{1,2}-$ ZHAO, J. ${ }^{1 *}$ \\ ${ }^{1}$ College of Architecture, Changan University \\ No.161 Changan Rd., Yanta Dist., Xi'an 710061, Shaanxi, China \\ ${ }^{2}$ Yuncheng Polytechnic, Yuncheng 0444000, Shanxi, China \\ *Corresponding author \\ e-mail:gyjemma@163.com/2016041002@chd.edu.cn/478531002@qq.com
}

(Received 24 $4^{\text {th }}$ Aug 2018; accepted $11^{\text {th }}$ Oct 2018)

\begin{abstract}
This paper takes Xi'an, which is a western city in China, experiencing the rapid urbanization, as the research object. It uses 2000 Landsat7 ETM+, 2010 Landsat5 TM and 2016 Landsat8 OLI images as data sources to inverse and normalize surface temperature. Thermal field intensity index (HFI) and urban heat island proportion index (UHPI) were introduced to quantitatively assess the temporal and spatial variation of heat island in Xi'an. Research results demonstrate: (1) From 2000 to 2016, the average temperature in urban areas increased from $32.34{ }^{\circ} \mathrm{C}$ in 2006 to $42.45{ }^{\circ} \mathrm{C}$ in 2016 , with an increase of $10.11{ }^{\circ} \mathrm{C}$ in 16 years. (2) From 2000 to 2016, the urban heat island area continuously increased, from $40.59 \mathrm{~km}^{2}$ in 2000 to $81.52 \mathrm{~km}^{2}$ in 2016, with an increase of about $100.87 \%$. UHPI increased from 0.036 in 2000 to 0.078 in 2016, which indicates the scientific rationality of the index to a certain extent. (3) According to the distribution law, the heat island scope and urban expansion reflect strong time-space consistency. In the 16 years, the distribution pattern of thermal environment changed from "central urban area distribution mode" to "built-up area distribution mode". (4) From the perspective of the distribution in administrative region, heat island effect was mainly distributed in the old areas such as Lianhu District and Xincheng District in 2000. Due to urban expansion, the phenomenon of "hollow heat island" appeared in 2010. In 2016, heat island effect was distributed in all six areas.
\end{abstract}

Keywords: temporal and spatial variation, heat island effect, TM satellite remote sensing image, urbanization, urban thermal environment, Xi'an

\section{Introduction}

While rapid urbanization brings economic development in China, it also brings adverse effects on urban climate, such as abnormal climate changes, intensified urban heat island effects, and frequent occurrence of extreme high temperature events. These problems have seriously threatened people's daily life. Therefore, it is gradually becoming the research focus to quantitatively study the changing trend of urban thermal environment, to discuss the evolution process of urban thermal environment and its influencing factors, and to reveal the formation mechanism and distribution law of urban heat island effect.

Since the remote sensing image has the characteristics of high resolution and wide coverage, domestic and foreign scholars mostly use thermal infrared remote sensing data to study the urban thermal environment. The existing research focuses on the inversion of surface temperature, the interaction between urban thermal environment and surface landscape, the response of urban heat island, the formation mechanism and influencing factors of urban heat island. Research on the quantitative definition and division of the intensity of urban heat island in different years and the law of distribution and evolution, especially on the inland cities in the central and western 
regions, is scarce. In terms of research methods, the atmospheric radiation correction method, single window algorithm, split window algorithm and ARCGIS/ENVI software are used to study the urban thermal field. However, most studies use brightness temperature as the main index of thermal environment evaluation, which cannot truly reflect the intensity of urban heat island effect. For example, Qin et al., took Ling County of Shandong Province as an example to compare and analyze the difference between surface temperature and brightness temperature of water body, farmland and village. The average difference was $2.51{ }^{\circ} \mathrm{C}, 3.52{ }^{\circ} \mathrm{C}$ and $5.10{ }^{\circ} \mathrm{C}$ respectively (Qin et al., 2004). Ding et al. found that the LST (Land Surface Temperature) of Fuzhou inversed by above three algorithms was about $1.9^{\circ} \mathrm{C}, 2.9^{\circ} \mathrm{C}$ and $5.3{ }^{\circ} \mathrm{C}$ higher than the brightness temperature (Ding et al., 2008). In order to accurately analyze the spatial difference of surface heat, the real LST should be retrieved through the satellite thermal infrared data. Brightness temperature for analysis could result in large errors (Tan et al., 2006).

Therefore, in order to accurately analysis the temporal and spatial pattern and evolution of thermal environment in Xi' an in different periods, this paper takes Xi'an as the research object, uses the atmospheric radiation correction method to retrieve the LST of Xi' an urban area in different periods by introducing the thermal field intensity index and the heat island proportion index, hoping to contribute to the research of Xi'an's urban thermal environment.

\section{Research Methods}

\section{Introduction to the Research Area}

$\mathrm{Xi}$ 'an City is located at $33.42^{\circ} \mathrm{N}-34.45^{\circ} \mathrm{N}$ and $107.40^{\circ} \mathrm{E}-109.49^{\circ} \mathrm{E}$, in the middle of Guanzhong Plain in China, neighboring Weihe River in the north and Qinling Mountains in the south (Figure 1). The territory is about $204 \mathrm{~km}$ long from the east to the west and about $116 \mathrm{~km}$ wide from the south to the north.

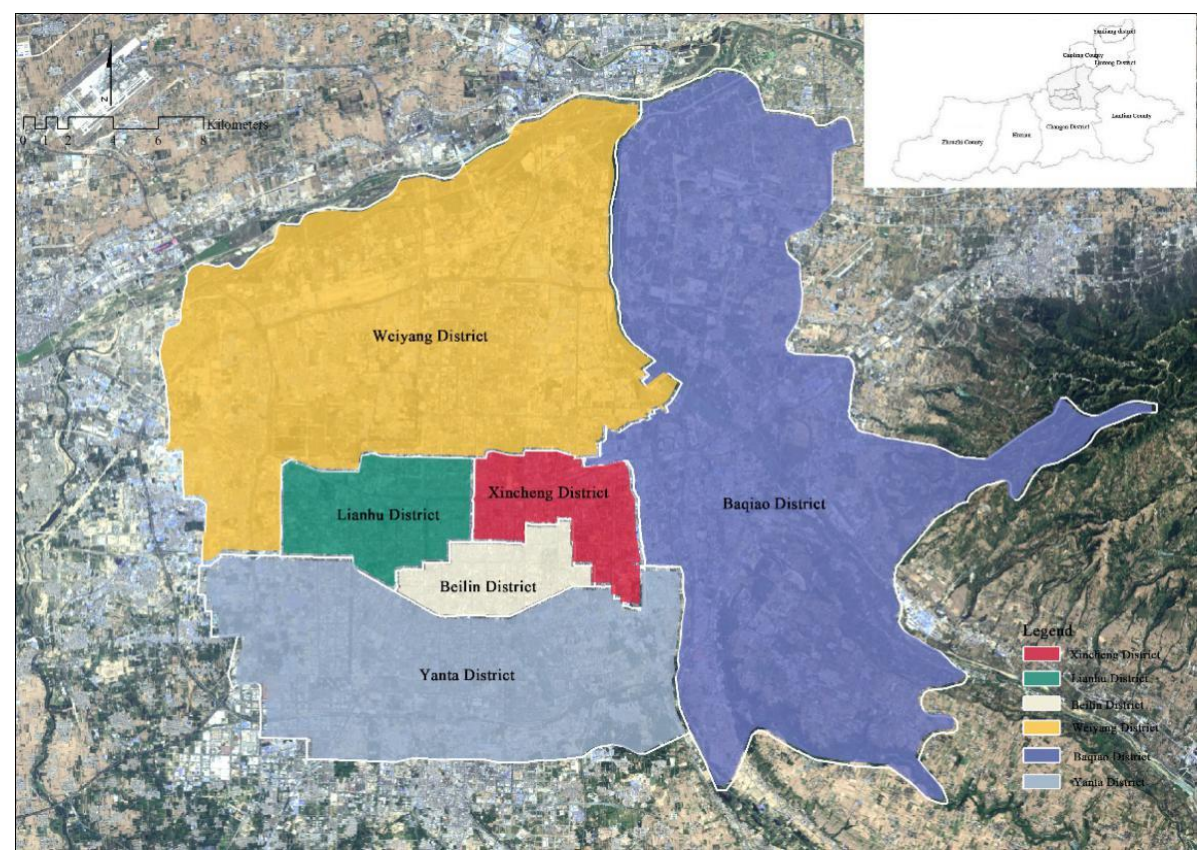

Figure 1. A map of the research area position 
The territory is about $204 \mathrm{~km}$ long from the east to the west and about $116 \mathrm{~km}$ wide from the south to the north. The total area is about $10108 \mathrm{~km}^{2}$, of which the urban area is $1066 \mathrm{~km}^{2}$. Xi'an is a sub-humid monsoon climate in warm temperate zone. The annual average temperature is about $15.5^{\circ} \mathrm{C}$, and the annual precipitation is about 600 $\mathrm{mm}$. There are 11 districts and 2 counties under the jurisdiction of $\mathrm{Xi}$ 'an, which are Weiyang District, Xincheng District, Beilin District, Lianhu District, Baqiao District, Yanta District, Yanliang District, Lintong District, Chang'an District, Gaoling District, Huyi District, Lantian County and Zhou County. In view of the characteristics of the heat island effect, this paper analyzes the temporal and spatial changes of the heat island in the six districts (Xincheng District, Beilin District, Lianhu District, Yanta District, Baqiao District and Weiyang District) within the third ring of Xi'an.

\section{Research Method}

Although the urban heat island effect may occur in all seasons of a year, it has high impact on residents lives in summer. Generally speaking, the four seasons are divided as follows. Spring is from March to May, summer is from June to August, autumn is from September to November, winter is from December to February. Therefore, this paper mainly studies the heat island effect during the summer months (from June to August).

In order to improve the research accuracy, the images with high quality (cloud free and noiseless) and the same or close season were selected. By comparing the image data, the spatial variation of thermal field in Xi'an urban area during the past 16 years was analyzed using the Landsat7 ETM+ on June 29, 2000, Landsat5 TM on June 17, 2010 and Landsat8 OLI on June 17, 2016 (as shown in Table 1).

Table 1. A list of remote sensing image data

\begin{tabular}{c|c|c|c}
\hline Year & 2000 & 2010 & 2016 \\
\hline Time & $2000 / 6 / 29$ & $2010 / 6 / 17$ & $2010 / 6 / 17$ \\
\hline Satellite & Landsat7 ETM SLC-on & Landsat4-5 TM & Landsat 8 OLI_TIRS \\
\hline Cloudiness & $0.47 \%$ & $1.87 \%$ & $0.03 \%$ \\
\hline Strip number & 127 & 127 & 127 \\
\hline Line number & 36 & 36 & 36 \\
\hline Longitude & 108.8074 & 108.8074 & 108.8074 \\
\hline Latitude & 34.6108 & 34.6108 & 34.6108 \\
\hline
\end{tabular}

At present, there are three main methods for retrieving surface temperature through Landsat TM/ETM thermal infrared data: atmospheric correction method (also known as radiative transfer equation-RTE), single channel algorithm and split window algorithm. By comparing the above three methods, the atmospheric correction method had clear principle, and the process of solving the problem requires only atmospheric profile parameters or abundant atmospheric data to get the surface temperature by software simulation. Although the single window algorithm is simple and accurate compared with atmospheric correction method, it is difficult to obtain multiple kinds of atmospheric parameters that need to be synchronized in the calculation process. The default parameter or standard parameter could lead to large error (Di et al., 2016). Reference 4 retrieved and analyzed the surface temperature by using the above methods. The results showed that when the real time sounding data were available, the root mean 
square error of land surface temperature obtained by the atmospheric correction method was the minimum (Huang et al., 2006). Therefore, this paper used the atmospheric correction method to retrieve the surface temperature using ENVI software. The basic principle is as below: First, the influence of atmosphere on surf ace thermal radiation is estimated. Second, the atmospheric influence is subtracted from the total thermal radiation observed by satellite sensor to obtain the surface thermal radiation intensity. Finally, the thermal radiation intensity is converted to the corresponding surface temperature. The specific method flow is shown in the diagram (Figure 2).

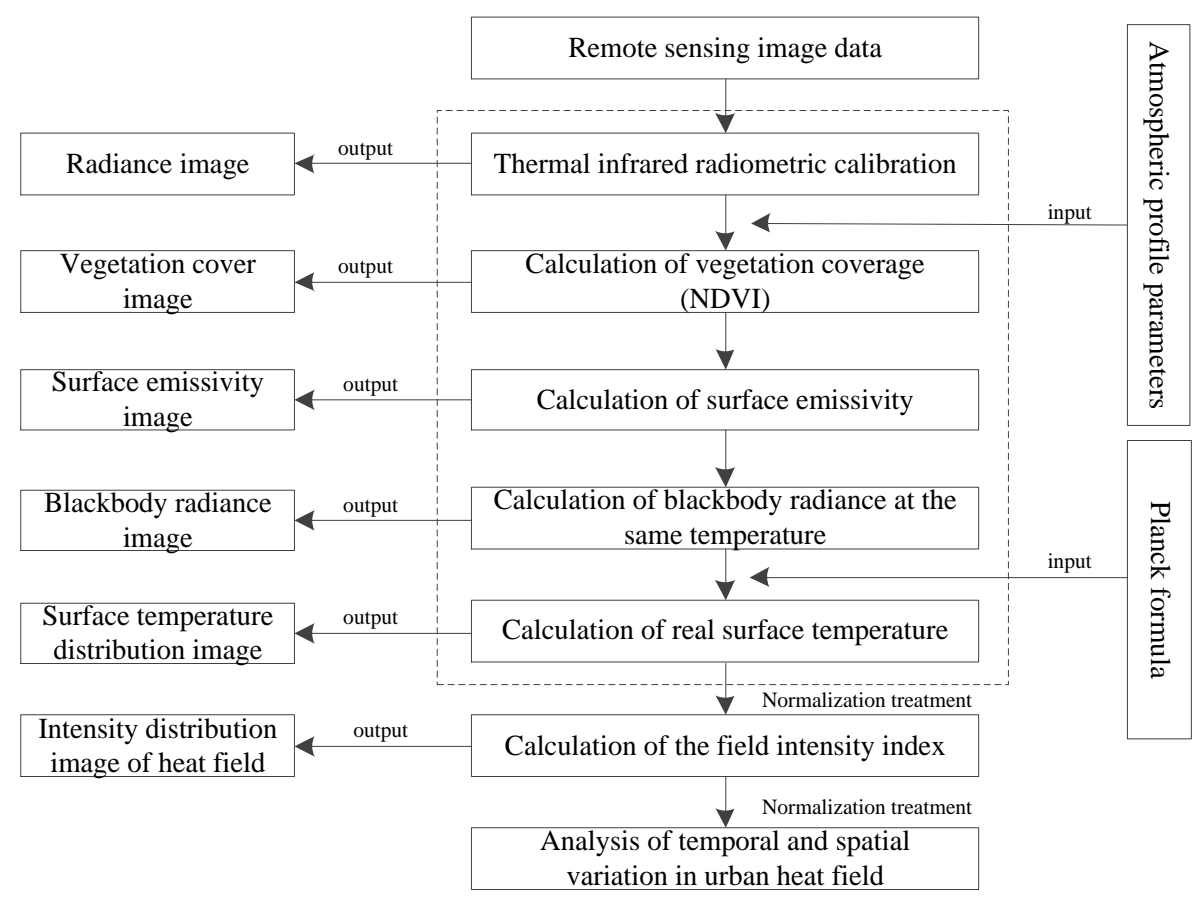

Figure 2. Inversion of surface temperature flow chart by atmospheric correction method

In order to eliminate the influence of the absolute temperature difference in different seasonal phases, this paper introduces the heat field intensity index (abbreviated as HFI) to normalize the surface temperature. HFI can clearly reflect the relative high temperature and low temperature range of the thermal field of the image. And it has the thermal field indication meaning. The expression is as follows (Equation 1):

$$
\mathrm{H}_{i}=\frac{T_{i}-T_{\min }}{T_{\max }-T_{\min }}
$$

where, $H_{i}$ is the heat field intensity exponent corresponding to the $i^{\text {th }}$ pixel, $T_{i}$ is the surface temperature, $T_{\min }$ is the minimum effective surface temperature in image region, and $T_{\max }$ is the maximum effective surface temperature in image region. Larger thermal field intensity index indicates that the more likely it is to be in the heat island range. By analyzing a large number of remote sensing images, the thermal intensity index is generally divided into 7 grades (as shown in Table 2): low temperature area, lower temperature area, secondary medium temperature area, medium temperature area, medium high temperature area, high temperature area and ultra-high temperature area, 
which can effectively reflect the size of urban heat island.

Table 2. Preliminary division and definition of surface heat field index

\begin{tabular}{c|c|c}
\hline Grade & Heat field intensity index & Definition \\
\hline 1 & $0-0.15$ & Low temperature area \\
\hline 2 & $0.15-0.3$ & Lower temperature area \\
\hline 3 & $0.3-0.45$ & Secondary medium temperature area \\
\hline 4 & $0.45-0.6$ & Medium temperature area \\
\hline 5 & $0.7-0.75$ & Medium high temperature area \\
\hline 6 & $0.75-0.9$ & High temperature area \\
\hline 7 & $0.9-1.0$ & Ultra-high temperature area \\
\hline
\end{tabular}

Urban Heat Proportion Index (abbreviated as UHPI) also is introduced in this paper. It can calculate the ratio of the heat island area to region area based on the urban space unit, and puts different weight to indicate the development degree of the heat island in the space unit. This index could more scientifically compare the change of urban heat island between different space units in different years. The larger the index, the more serious the heat island effect. The index has been successively used by the Ministry of Environmental Protection and the Ministry of Housing Urban-Rural Construction as an index to evaluate the urban ecological environment and the urban environmental performance. It has been authorized and widely used in the research on the change of the urban thermal environment. The basic formula is as follows (Equation 2):

$$
\mathrm{UHPI}=\frac{1}{100 m} \sum_{i}^{n} w_{i} p_{i}
$$

where, UHPI is urban heat proportion index. $m$ is the thermal field intensity grade. $i$ is the temperature grade of suburb higher than urban area. $n$ is the temperature grade of urban area higher than suburb. $w_{i}$ is the weight of the $i^{t h}$ grade, which is the grade value. $p_{i}$ is the proportion of area at the $i$ grade. In this study, according to the above defined thermal field intensity grade, $m=7$. The three grades of ultra-high temperature area, high temperature area and medium high temperature area are mainly distributed in urban area, which represent the urban heat island area. The temperature in the suburb is mainly below the medium temperature area. Therefore, $n=3$ in this research. The grades of ultra-high temperature area, high temperature area and medium high temperature area are 7,6 and 5, respectively.

\section{Results and discussion}

\section{Dynamic Change of Surface Temperature Retrieval in Xi'an}

The remote sensing images in the three periods were processed through the above method, and the 2000-2016 surface temperature distribution diagram is obtained (as shown in the following Figure 3). From the retrieval results of surface temperature in the third periods, it can be seen that the regions with higher temperature are mainly distributed in the built-up area and the area with poor vegetation coverage. From 2010 
to 2016 , the average temperature and the maximum temperature gradually increased. The temperature ranged from $21.25{ }^{\circ} \mathrm{C}$ to $48.03{ }^{\circ} \mathrm{C}$ in 2000 , and the average temperature was $32.34{ }^{\circ} \mathrm{C}$. In 2010 , the range of surface temperature was from $26.27{ }^{\circ} \mathrm{C}$ to $51.52{ }^{\circ} \mathrm{C}$, with an average temperature of $38.65{ }^{\circ} \mathrm{C}$. The surface temperature ranged from $24.01{ }^{\circ} \mathrm{C}$ to $60.84{ }^{\circ} \mathrm{C}$ in 2016 , and the average temperature was $42.45{ }^{\circ} \mathrm{C}$. The average temperature increased from $32.34{ }^{\circ} \mathrm{C}$ in 2000 to $42.45{ }^{\circ} \mathrm{C}$ in 2016 , with an increase of $10.11^{\circ} \mathrm{C}$ in 16 years (as shown in the following Figure 4).

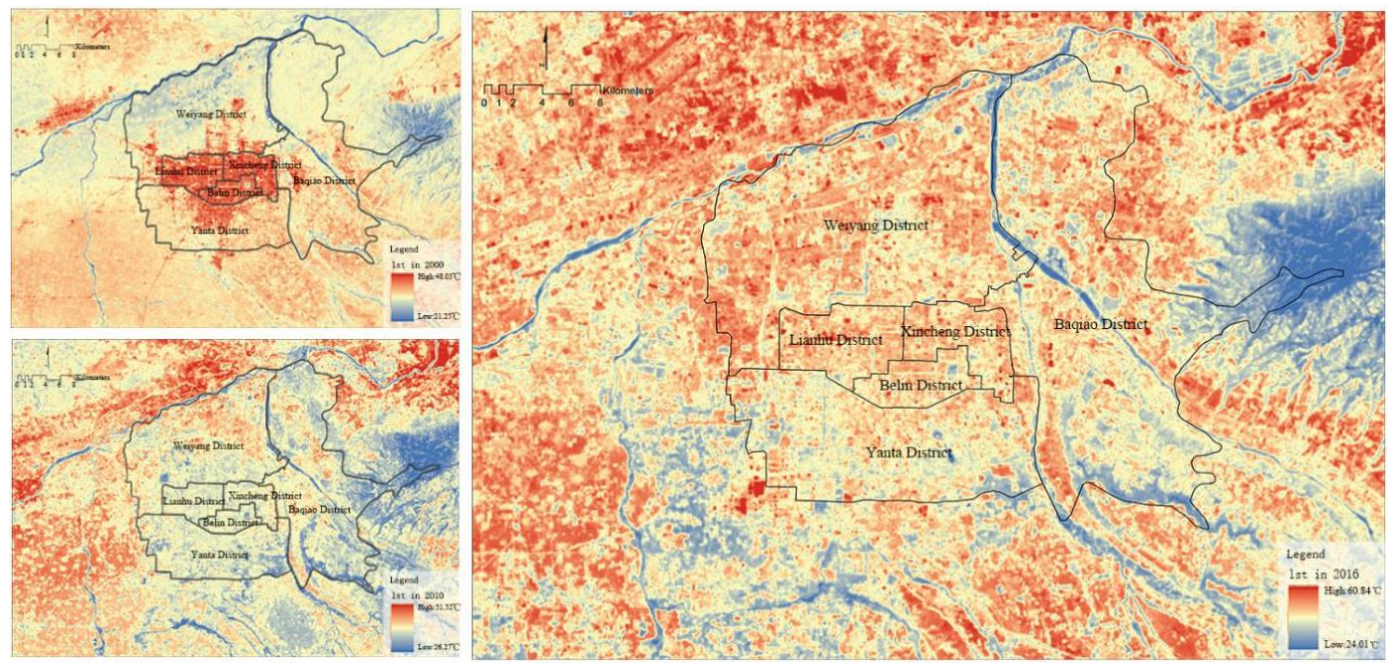

Figure 3. LST distribution from 2000 to 2016

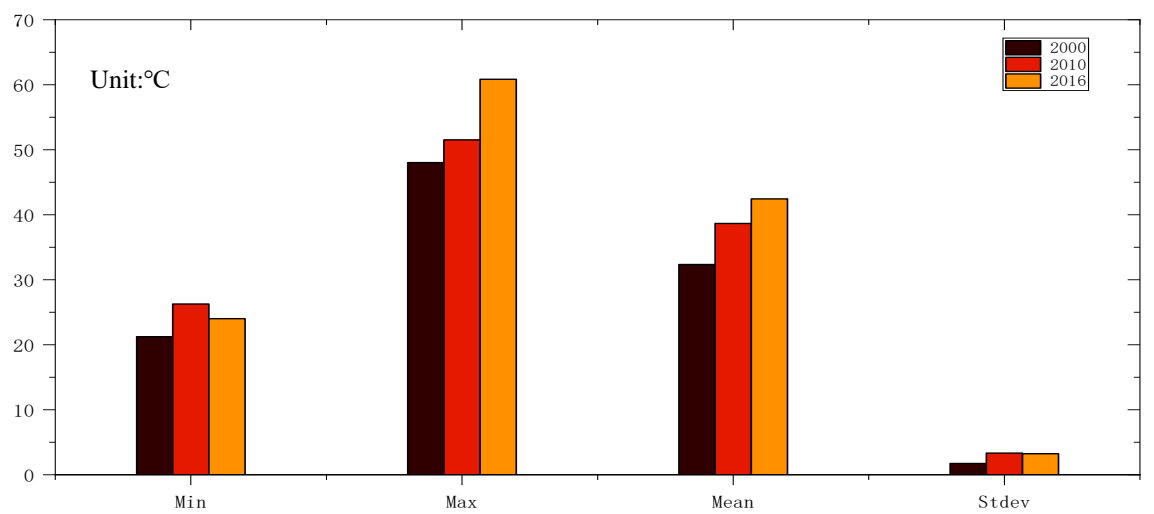

Figure 4. Maximum, minimum, mean and standard deviation of LST from 2000 to 2016

In order to deeply analyze the distribution characteristics of LST in urban area, the surface temperature images of the six districts were extracted through ArcGIS, and the section line was drawn with Bell Tower, the center of city wall in the Ming Dynasty as the benchmark, the south street-north street as the south-north axis, and east avenuewest avenue as the east-west axis (as shown in the Figures 5, 6 and 7). It can be seen from the section lines in WE direction and NS direction that the lower LST indicates higher vegetation coverage and lower population density, combining with the corresponding images. Water body and green space have obvious cooling effect on the area. Otherwise, the LST is relatively high. From the perspective of time dimension, the 
profile lines of 2000 are all high in the middle and slightly lower on both ends. In 2016, the temperature on both ends increased gradually, and the temperature in some areas were even higher than the middle part. The relative difference of urban thermal environment was reduced, and the thermal environment pattern gradually changed from "distributed central district" to "distributed built-up area". This indicates that the urban heat island effect and urban expansion show significant temporal and spatial consistency.
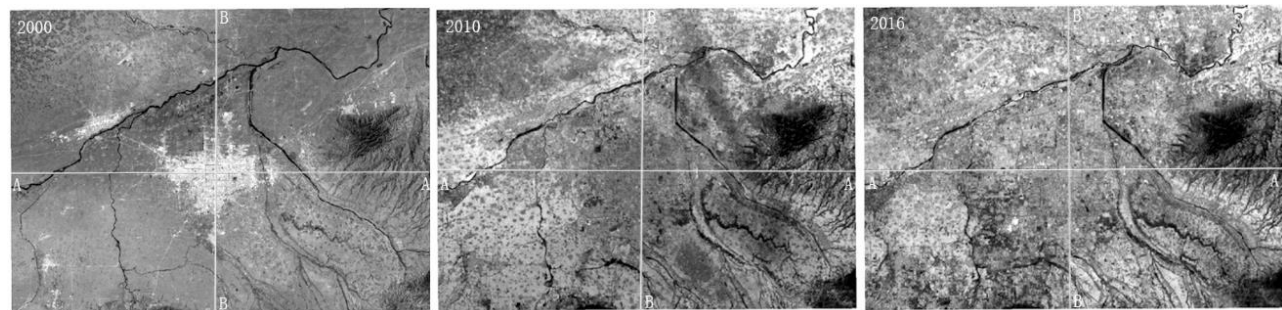

Figure 5. Positions of LST profiles across the study area from 2000 to 2016

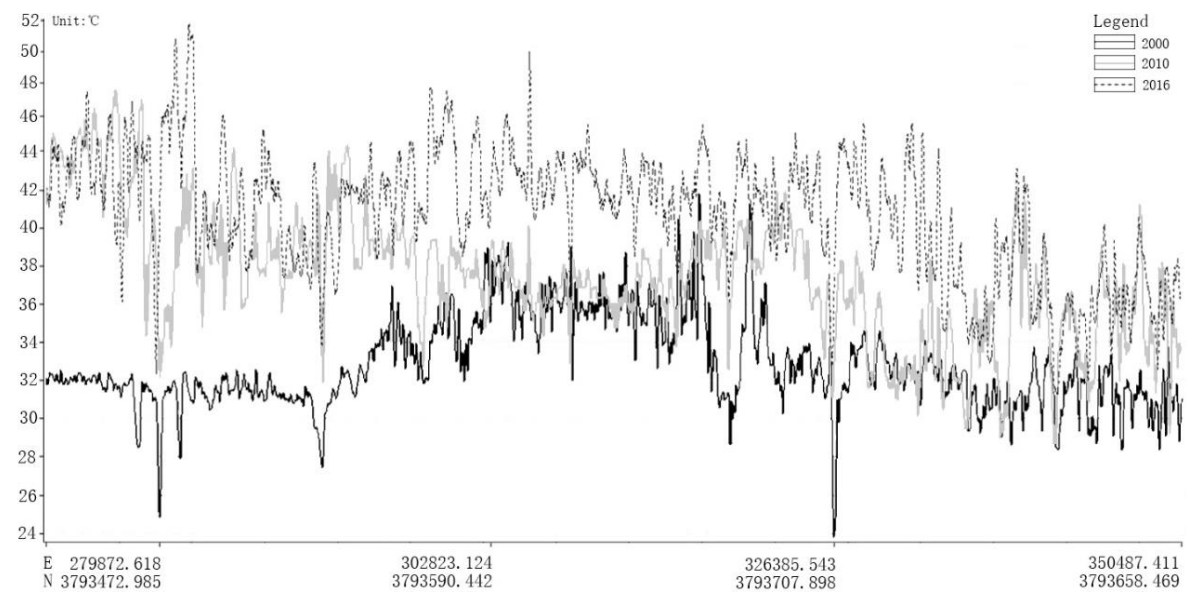

Figure 6. LST distribution of the A-A section across the study area from 2000 to 2016

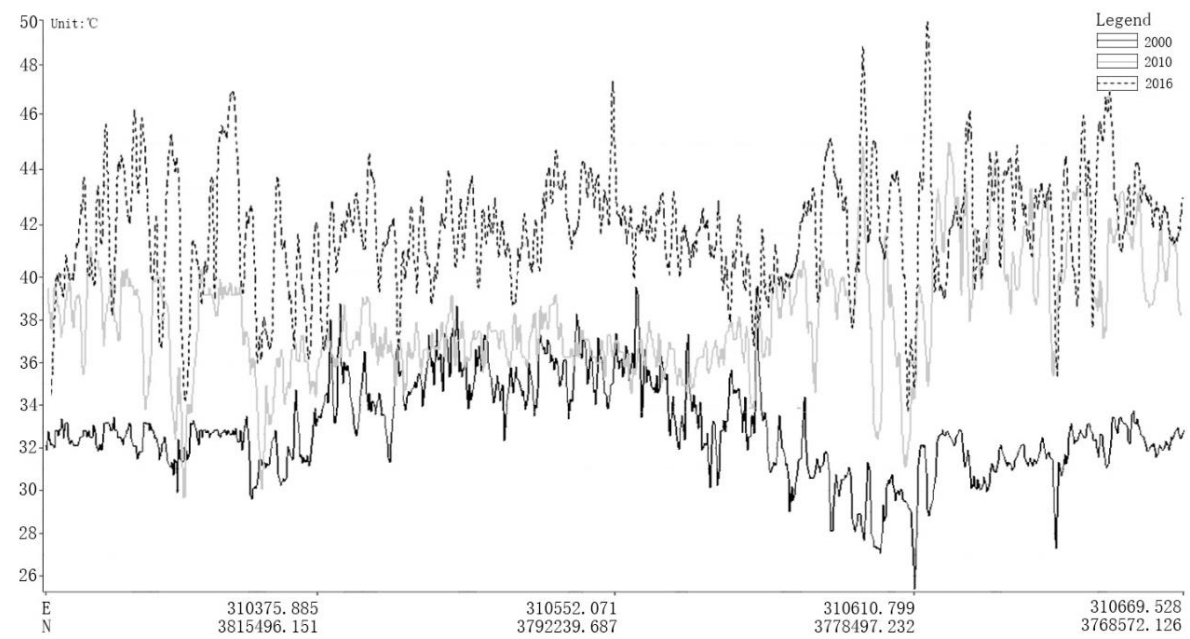

Figure 7. LST distribution of the B-B section across the study area from 2000 to 2016 


\section{Spatial Distribution Characteristics of Surface Temperature Grade in Xi'an}

As mentioned above, in order to study the temporal variation of urban heat island by using the temperature inversion of different phase images, this paper used the brightness temperature normalization method to reduce the influence of seasonal phase difference. The thermal infrared images of different phases were compared, and the heat field intensity index (HFI) and Urban heat proportion index (UHPI) were introduced to study the change of urban heat island quantitatively. In order to study the urban heat island of Xi'an, the administrative boundary of the six districts of Xi'an City (Xincheng District, Beilin District, Lianhu District, Yanta District, Baqiao District and Weiyang District) was further used to perform the superposition mask operation on the thermal field intensity grade image. The distribution map of urban bright temperature grade was drawn, and the area of different grades was calculated (as shown in Figures 8, 9 and Table 2).
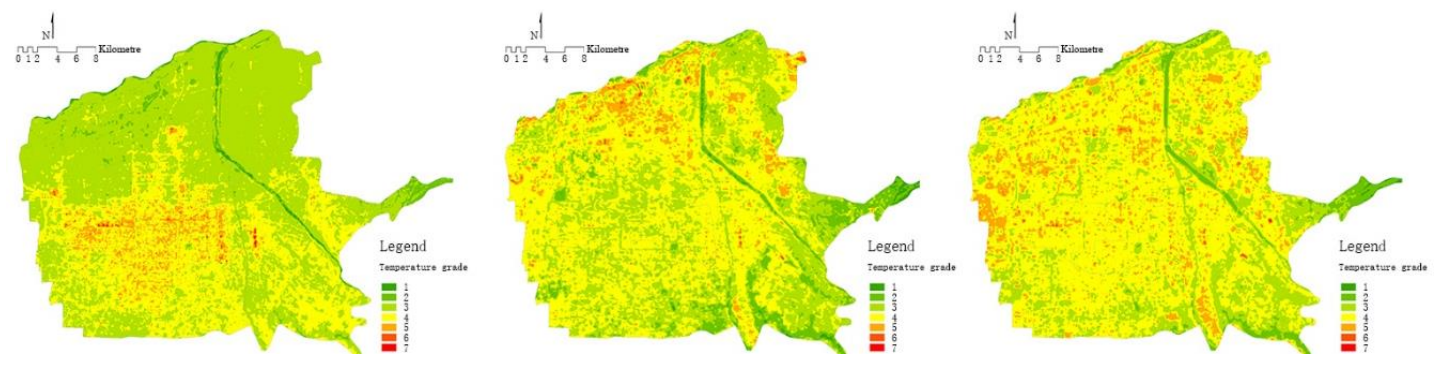

Figure 8. The distribution map of the intensity grade of the heat field in the six districts of Xi'an City
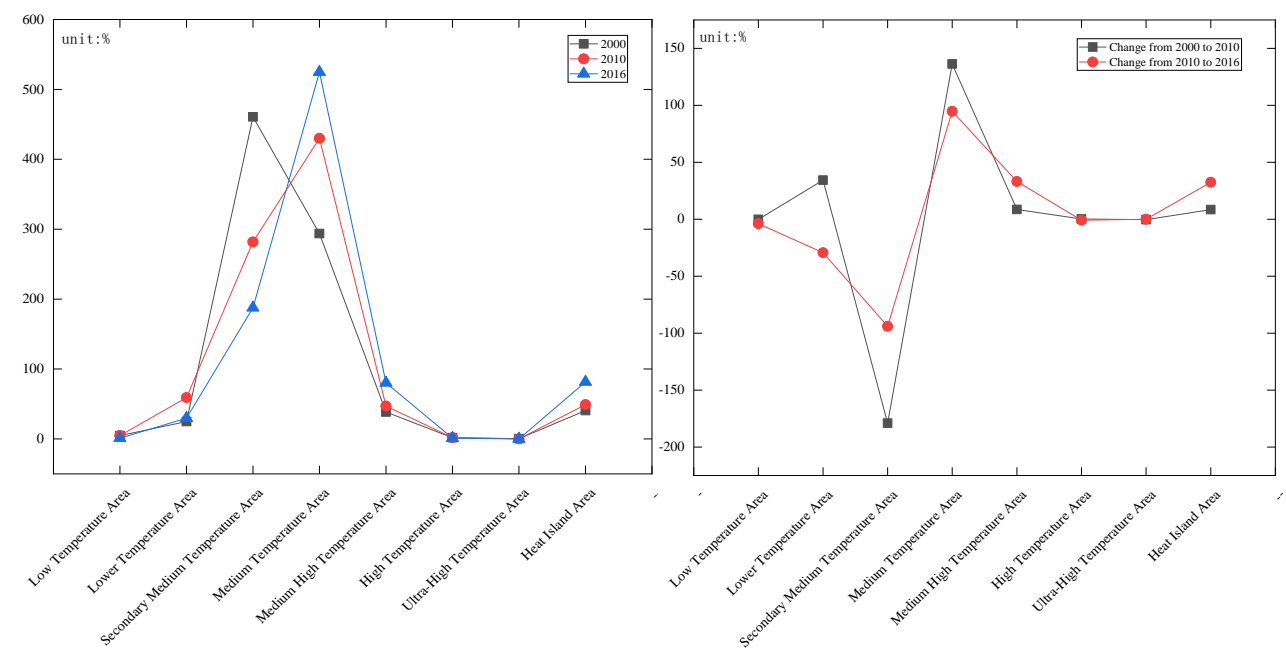

Figure 9. Area distribution map and area change map of six districts in Xi'an

From the qualitative point of view, according to the intensity distribution map of the thermal field in the six districts of Xi'an City, the heat island effect in Xi'an city showed an overall increasing trend from 2000 to 2016. In 2000, the urban heat island effect was concentrated, continuous and distributed in a plane. After 2010, the urban heat island effect was dispersed. The regional heat island aggregation in urban heat island effect was reduced. In 2000, the temperature of Xi'an urban area was obviously higher than 
that of the peripheral area, showing the spatial characteristics of decreasing gradually from inside to outside. In 2010, the number and high temperature areas became larger, and the distribution was wider, with obvious characteristics of urban heat island effect. In 2016, the intensity of heat island continuously increased, and the heat island area gradually changed from centralized pattern to decentralized pattern due to the expansion of peripheral cities and the regulating action of vegetation and water body in city. Therefore, strengthening the construction of urban green space and rational planning of water body can further reduce the urban heat island effect in Xi'an.

Table 2. List of intensity area and percentage of thermal field in six districts of Xi'an City

\begin{tabular}{c|c|c|c|c|c|c|c|c}
\hline \multirow{3}{*}{ Year } & Grade & 1 & 2 & 3 & 4 & 5 & 6 & 7 \\
\cline { 2 - 9 } & $\begin{array}{c}\text { Grade } \\
\text { definition }\end{array}$ & LTA & LerTA & SMTA & MTA & MHTA & HTA & UHTA \\
\hline \multirow{2}{*}{2000} & Area & 4.78 & 24.81 & 460.80 & 293.68 & 38.48 & 1.79 & 0.32 \\
\cline { 2 - 10 } & Proportion & $0.58 \%$ & $3.01 \%$ & $55.88 \%$ & $35.61 \%$ & $4.67 \%$ & $0.22 \%$ & $0.04 \%$ \\
\hline \multirow{2}{*}{2010} & Area & 4.69 & 59.13 & 281.75 & 430.06 & 47.02 & 2.00 & 0.01 \\
\cline { 2 - 10 } & Proportion & $0.57 \%$ & $7.17 \%$ & $34.17 \%$ & $52.15 \%$ & $5.70 \%$ & $0.24 \%$ & $0.00 \%$ \\
\hline \multirow{2}{*}{2016} & Area & 0.89 & 29.73 & 187.71 & 524.82 & 80.26 & 1.22 & 0.04 \\
\cline { 2 - 10 } & Proportion & $0.11 \%$ & $3.61 \%$ & $22.76 \%$ & $63.64 \%$ & $9.73 \%$ & $0.15 \%$ & $0.00 \%$ \\
\hline \multirow{2}{*}{\begin{tabular}{c} 
Change from \\
\cline { 2 - 9 }
\end{tabular}} & Area & -0.09 & 34.32 & -179.05 & 136.37 & 8.54 & 0.21 & -0.30 \\
\cline { 2 - 9 } to 2010 & Rate of change & $-1.93 \%$ & $138.34 \%$ & $-38.86 \%$ & $46.44 \%$ & $22.19 \%$ & $11.86 \%$ & $-95.87 \%$ \\
\hline \multirow{2}{*}{$\begin{array}{c}\text { Change from } \\
2000 \text { to } 2010\end{array}$} & Area & -3.80 & -29.40 & -94.04 & 94.76 & 33.24 & -0.78 & 0.02 \\
\cline { 2 - 9 } & Rate of change & $-81.08 \%$ & $-49.72 \%$ & $-33.38 \%$ & $22.03 \%$ & $70.69 \%$ & $-38.96 \%$ & $179.27 \%$ \\
\hline
\end{tabular}

Remarks: 1) LTA: Low Temperature Area; 2) LerTA: Lower Temperature Area; 3) SMTA: Secondary Medium Temperature Area; 4) MTA: Medium Temperature Area; 5) MHTA: Medium High Temperature Area; 6) HTA: High Temperature Area; 7) UHTA: Ulter-high Temperature Area

From the quantitative point of view, it can be seen from the above table (Table 2) that the area of the medium temperature zone, secondary high temperature zone, high temperature zone and ultra-high temperature zone continuously expanded from 2000 to 2016, and the low temperature zone showed a declining trend. From 2000 to 2010, the area of the secondary high temperature zone and high temperature zone in the six districts in Xi'an has been expanded by $8.54 \mathrm{~km}^{2}$ and $0.21 \mathrm{~km}^{2}$, with an increase of about $22.19 \%$ and $11.86 \%$, respectively. Although the area of the ultra-high temperature zone decreased by $0.30 \mathrm{~km}^{2}$, the overall heat island area still increased by $8.45 \mathrm{~km}^{2}$ from 2000 to 2010 , with an increase of $20.82 \%$. The area of the low temperature zone decreased by $0.09 \mathrm{~km}^{2}$, with a decrease of $1.88 \%$. From 2010 to 2016 , the area of the secondary high temperature zone and the ultra-high temperature zone increased by $33.23 \mathrm{~km}^{2}$ and $0.02 \mathrm{~km}^{2}$, with the increase of about $70.69 \%$ and $200 \%$. Although the area of high temperature area decreased by $0.77 \mathrm{~km}^{2}$, the area of heat island has still expanded by $32.48 \mathrm{~km}^{2}$, with an increase of about $39.84 \%$. The area of low temperature zone decreased by $3.80 \mathrm{~km}^{2}$, with a decrease of $81.02 \%$. The urban heat island ratio indices of Xi' an City in 2000, 2010 and 2016 were UHPI2000 $=0.036, \mathrm{UHPI}_{2010}=0.050$ and $\mathrm{UHPI}_{2016}=0.078$, respectively. This indicates that the heat island effect in the six districts of Xi' an City increased from 2000 to 2016. Obviously, it is further verified that the brightness temperature normalization method, HFI and UHPI can objectively and quantitatively reflect the changes of urban heat island. 


\section{Quantitative Analysis of Heat Island effect Boundary Evolution}

In order to concretely reflect the spatial distribution of urban heat island in central urban area of Xi'an, ArcGIS software was used to divide the thermal field intensity grade map of the research area combined with administrative boundary to get the value and proportion of each region's geothermal grade area. The detailed statistics are provided in the Figure 10 and Table 3 as below.
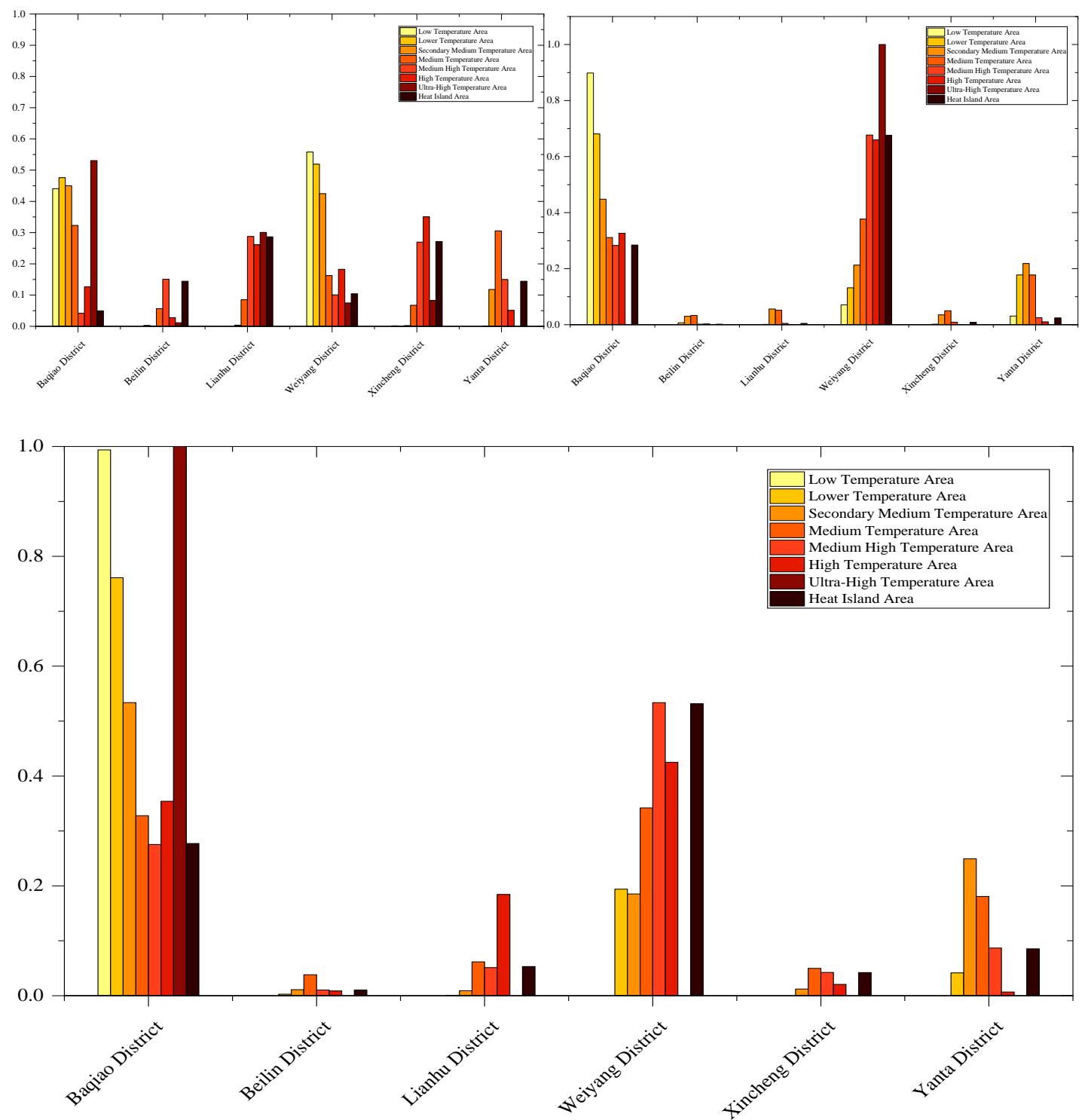

Figure 10. Figure of intensity area ratio of each thermal area in each administrative area of $X i^{\prime}$ an from 2000 to 2016

As shown in the Table 3, in 2000, the heat island area was mainly concentrated in the densely populated old urban area inside the city wall. The area of heat islands in Lianhu District and Xincheng District is relatively large, accounting for about $28.643 \%$ and $27.151 \%$ of the total area of heat island, which are followed by Yanta District and Beilin District with the proportions of $14.429 \%$ and $14.423 \%$. The proportions of Weiyang District and Baqiao District in low temperature zone, secondary temperature 
zone and secondary medium temperature zone are great, which are $55.802 \%$ and $44.048 \%, 51.931 \%$ and $47.602 \%$, and $42.477 \%$ and $51.931 \%$, respectively. The area of heat island in Weiyang District and Baqiao District occupy large proportions, which were about $67.637 \%$ and $28.445 \%$ of the total area. The proportion of Baqiao District in the low temperature zone, low temperature zone and secondary medium temperature area is the largest, accounting for $89.852 \%, 68.089 \%$ and $44.783 \%$, respectively. The scope of the heat island further expanded in 2016. However, the intensity grade of local regional heat island in the old urban area decreased and distributed dispersedly. The area proportions of the districts are the same as those in 2010. The proportions of heat island area in Weiyang District and Baqiao District are still larger, but are slightly lower than that in 2010, accounting for $53.167 \%$ and $27.706 \%$ of the total heat island area. Baqiao District still occupies the largest proportions in the low temperature zone, the lower temperature zone, the secondary modium temperature zone, and slightly increased compared with 2010, accounting for about $99.382 \%, 76.103 \%$ and $53.360 \%$.

Table 3. Table of thermal intensity area in each administrative area of Xi'an from 2000 to 2016

\begin{tabular}{|c|c|c|c|c|c|c|c|c|c|}
\hline & & $\operatorname{LTA}\left(\mathbf{k m}^{2}\right)$ & $\mathbf{L}_{\mathrm{er}} \mathbf{T A}\left(\mathrm{km}^{2}\right)$ & $\operatorname{SMTA}\left(\mathbf{k m}^{2}\right)$ & $\operatorname{MTA}\left(\mathbf{k m}^{2}\right)$ & $\operatorname{MHTA}\left(\mathbf{k m}^{2}\right)$ & $\operatorname{HTA}\left(\mathbf{k m}^{2}\right)$ & $\operatorname{UHTA}\left(\mathrm{km}^{2}\right)$ & $\operatorname{HIA}\left(\mathrm{km}^{2}\right)$ \\
\hline \multirow{6}{*}{2000} & $\begin{array}{l}\text { Baqiao } \\
\text { District }\end{array}$ & 2.107 & 11.810 & 207.527 & 94.879 & 1.609 & 0.226 & 0.168 & 2.003 \\
\hline & Beilin District & 0.000 & 0.070 & 0.543 & 16.590 & 5.800 & 0.050 & 0.004 & 5.853 \\
\hline & $\begin{array}{l}\text { lianhu } \\
\text { District }\end{array}$ & 0.000 & 0.000 & 1.690 & 25.033 & 11.062 & 0.467 & 0.095 & 11.624 \\
\hline & $\begin{array}{l}\text { Weiyang } \\
\text { District }\end{array}$ & 2.670 & 12.884 & 195.738 & 47.755 & 3.879 & 0.326 & 0.024 & 4.228 \\
\hline & $\begin{array}{c}\text { Xincheng } \\
\text { District }\end{array}$ & 0.007 & 0.014 & 1.018 & 19.759 & 10.366 & 0.626 & 0.026 & 11.019 \\
\hline & Yanta District & 0.000 & 0.031 & 54.289 & 89.667 & 5.765 & 0.091 & 0.000 & 5.856 \\
\hline \multirow{6}{*}{2010} & $\begin{array}{l}\text { Baqiao } \\
\text { District }\end{array}$ & 4.216 & 40.261 & 126.179 & 133.723 & 13.295 & 0.652 & 0.000 & 13.946 \\
\hline & Beilin District & 0.000 & 0.402 & 8.438 & 14.128 & 0.082 & 0.005 & 0.000 & 0.087 \\
\hline & $\begin{array}{l}\text { lianhu } \\
\text { District }\end{array}$ & 0.000 & 0.079 & 15.777 & 22.266 & 0.223 & 0.002 & 0.000 & 0.225 \\
\hline & $\begin{array}{l}\text { Weiyang } \\
\text { District }\end{array}$ & 0.332 & 7.777 & 59.917 & 162.086 & 31.831 & 1.318 & 0.013 & 33.161 \\
\hline & $\begin{array}{c}\text { Xincheng } \\
\text { District }\end{array}$ & 0.000 & 0.103 & 9.879 & 21.418 & 0.418 & 0.000 & 0.000 & 0.418 \\
\hline & Yanta District & 0.144 & 10.509 & 61.565 & 76.434 & 1.171 & 0.021 & 0.000 & 1.191 \\
\hline \multirow{6}{*}{2016} & $\begin{array}{l}\text { Baqiao } \\
\text { District }\end{array}$ & 0.882 & 22.628 & 100.162 & 172.070 & 22.115 & 0.431 & 0.036 & 22.583 \\
\hline & Beilin District & 0.000 & 0.088 & 2.049 & 20.065 & 0.842 & 0.011 & 0.000 & 0.853 \\
\hline & $\begin{array}{c}\text { lianhu } \\
\text { District }\end{array}$ & 0.000 & 0.010 & 1.675 & 32.324 & 4.113 & 0.225 & 0.000 & 4.337 \\
\hline & $\begin{array}{l}\text { Weiyang } \\
\text { District }\end{array}$ & 0.005 & 5.770 & 34.754 & 179.406 & 42.818 & 0.518 & 0.000 & 43.337 \\
\hline & $\begin{array}{c}\text { Xincheng } \\
\text { District }\end{array}$ & 0.000 & 0.000 & 2.275 & 26.112 & 3.405 & 0.025 & 0.000 & 3.430 \\
\hline & Yanta District & 0.000 & 1.237 & 46.796 & 94.840 & 6.962 & 0.008 & 0.000 & 6.971 \\
\hline
\end{tabular}

Remarks: 1) LTA: Low Temperature Area; 2) LerTA: Lower Temperature Area; 3) SMTA: Secondary Medium Temperature Area; 4) MTA: Medium Temperature Area; 5) MHTA: Medium High Temperature Area; 6) HTA: High Temperature Area; 7)UHTA: Ulter-high Temperature Area; 8)HIA: Heat Island Area

In order to clearly and intuitively reveal the distribution of heat island in Xi' an urban area, the thermal field intensity grade map was further processed in ArcGIS, and the 
heat island area of urban area from 2000 to 2016 was extracted and visualized (as shown in Figure 11). Combined with the actual situation of Xi' an City, in 2000, the urban construction was mainly concentrated in the Second Ring Road, and the population of the region was relatively dense. As a result, the area of heat islands in Lianhu District and Xincheng District was relatively large. In 2010, the heat island area began to appear in the north, west and southwest of the second ring, and the heat island effect within the second ring was weakened. The "hollow heat island" phenomenon occurred. As a result of the large-scale construction of the old urban periphery, there are many new industrial areas, enterprises concentrated areas, stations, commercial districts, and development areas. Due to slow development and factory stagnation, the scope and intensity of the heat island in the eastern region did not increase. Owing to the high vegetation and water coverage of Qujiang River in the southeast, the heat island intensity decreased despite of the development. In 2016, the scope of the heat island was further expanded to the north and the west obviously, showing dispersed distribution, which was resulted from the development and construction of the economic and technological development zone in the northern suburb, the western industrial zone and the high and new technology development zone in recent years. The development in the south and the east was mainly concentrated in the university town and Qujiang New District. There are a large number of parks, large areas of water and good surrounding green conditions, such as: Tang Paradise and Qujiang Ruins Park. As a result, the urban heat island effect is not obvious.

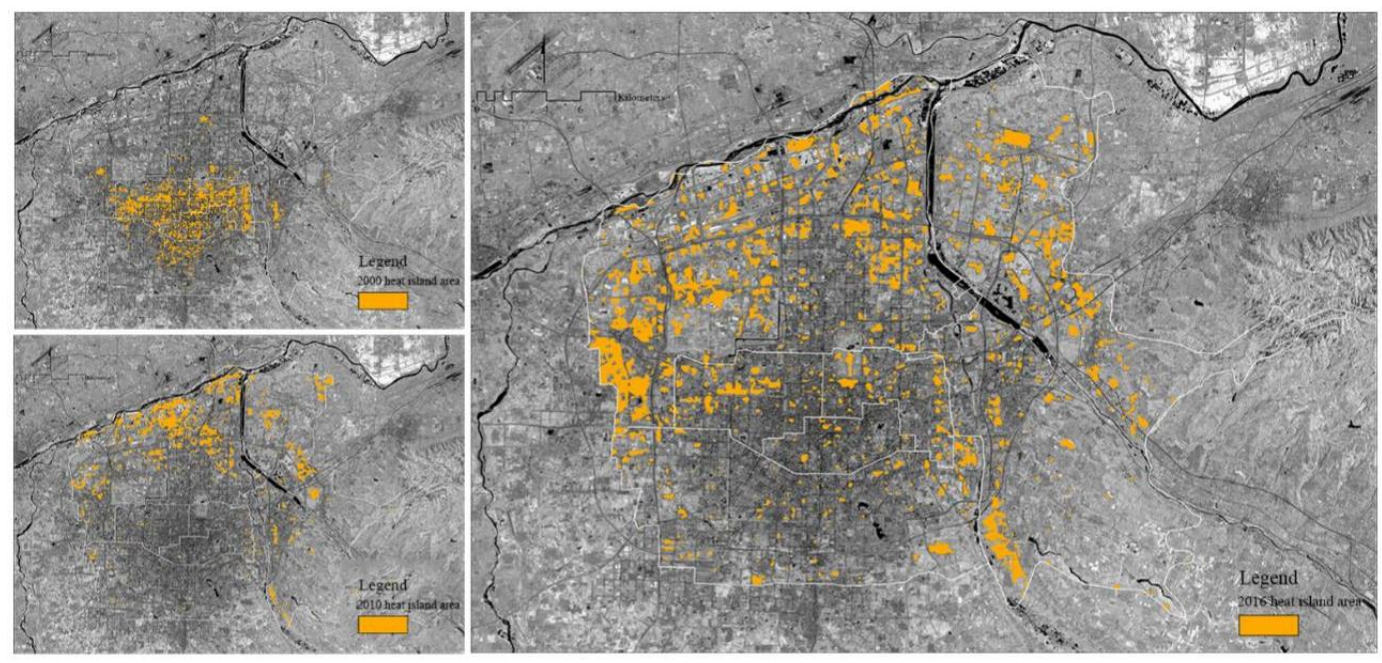

Figure 11. Regional distribution map of Urban Heat Island from 2000 to 2016

\section{Conclusions}

(1) According to the surface temperature inversion results, from 2000 to 2016, the average temperature in urban areas increased from $32.34^{\circ} \mathrm{C}$ in 2000 to $42.45^{\circ} \mathrm{C}$ in 2016 , with an increase of $10.11^{\circ} \mathrm{C}$ in 16 years. The maximum temperature increased from $48.03^{\circ} \mathrm{C}$ in 2000 to $60.84^{\circ} \mathrm{C}$ in 2016 . The thermal field profile in 2000 in WE/NS is low in the middle and high at both ends, which indicates obvious heat island effect in old urban area. After 2010, the temperature at both ends in WE/NS direction increased gradually. The temperature of some areas was even higher than that of the old urban area, which indicated that the heat island effect gradually extended to the periphery. 
(2) From the perspective of the spatial distribution of surface temperature grade, although the area of ultra-high temperature zone decreased slightly, the area of high temperature area and secondary high temperature area continuously increased, and the overall heat island effect of urban area in Xi'an City increased from 2000 to 2016. To be specific, the area of heat island increased from $40.59 \mathrm{~km}^{2}$ in 2000 to $81.52 \mathrm{~km}^{2}$ in 2016 , with an increase rate of $100.87 \%$. UHPI increased from 0.036 in 2000 to 0.078 in 2016.

(3) As for the distribution law of the heat island effect, from 2000 to 2016, the regional space of the heat island gradually changed from centralized patter to decentralized patter. Generally speaking, the area with high vegetation coverage, low building density, greenbelt and water body has lower regional heat island effect. Heat island region shows high temporal and spatial consistency degree with urban expansion. Therefore, urban heat island effect can be alleviated by reasonable planning and transformation.

(4) In term of administrative division, the heat island effect was mainly distributed in the Lianhu District and Xincheng District within the second ring in 2000. After 2010, the heat island effect gradually expanded to the outer four administrative regions, and the "hollow heat island" phenomenon appeared in 2010. In 2016, the heat island effect was distributed in all the six districts, but the area of Weiyang District and Baqiao district occupied large proportions, which were about $53.167 \%$ and $27.706 \%$.

Based on the atmospheric correction method, the surface temperature of Xi'an urban area was inversed. HFI and UHPI were introduced to quantitatively evaluate the temporal and spatial variation of the thermal field intensity in Xi'an. The research results have certain reference value for subsequent research. However, due to the lack of synchronous meteorological data when the satellite passes, the atmospheric parameters were calculated by using the atmospheric correction parameter calculator. Meanwhile, with the limited data source, the images of the three periods were collected at different dates, which had certain impact on the results. These limitations will be further improved in the future research work.

Acknowledgements. The research was founded within the project No. 51678058 entitled: "The Influence Mechanism and Control of Urban Space Composition on the Distribution of Suspended Particles", supported by National Natural Science Foundation of China.

\section{REFERENCES}

[1] Balcik, F. (2014): Determining the Impact of Urban Components on Land Surface Temperature of Istanbul by Using Remote Sensing Indices. - Environ. Monit. Assess. 186(2): 859-872.

[2] Chander, G., Markham, B. L., Barsi, J. A. (2007): Revised Landsat-5 thematic mapper radiometric calibration. - Geoscience \& Remote Sensing Letters IEEE 4(3): 490-494.

[3] Chen, L., Jiang, R., Xiang,W. (2016): Surface Heat Island in Shanghai and Its Relationship with Urban Development from 1989 to 2013. - Adv. Meteorol.: 1-15.

[4] Di, Y., Zheng, Z., Zhang, B., Yin, H. (2016): Study on Dynamic Evolvement Process of the Urban Heat Island in Xi'an. - Journal Xi' an University of Architecture \& Technology (Natural Science Edition) 48(4): 551-555.

[5] Ding, F., Xu, H. (2008): Comparison of Three Algorithms for Retrieving Land Surface Temperature from Landsat TM Thermal Infrared Band. - Journal of Fujian Normal University (Natural Science Edition) 24(1): 91-96.

[6] Fan, C., Myint, S., Zheng, B. (2015): Measuring the Spatial Arrangement of Urban 
Vegetation and Its Impacts on Seasonal Surface Temperatures. - Prog. Phys. Geogr. 39(2): 199-219.

[7] Gao, X., Wu, G. X., Du, G. Y., Li, C. P., Shen, H. F. (2015): A Spatio-temporal Changes of Thermal Landscape Pattern Based on a Multifractal Model: a Case Study of Zhengzhou City. - Acta Ecologica Sinica 35(20): 6774-6787.

[8] Grădinaru, S. R., Loja, C. L., Onose, D. A., Gavrilidis, A. A., Patru-Stupariu, I., Kienast, F., Hersperger, A. M. (2015): Land Abandonment As a Precursor of Builtup Development at the Sprawling Periphery of Former Socialist Cities. - Ecol. Indic. 57: 305-313.

[9] Guo, Q., Zhu, Y. (2016): Analyzing the Thermal Environment Simulation for Relieving Heat Island Effect: A Case Study on the City of Xi'an. - Ecological Economy 32(3): 161164.

[10] He, X., Ye, X., Ma, W., Wang, C. (2017): Study of the Effects of Urban Underlying Surface Changing on the Air Pollution Diffusion in Hangzhou. - Science Technology and Engineering 17(11): 122-130.

[11] Hu, S., Yang, S., Li, W., Zhang, C., Xu, F. (2016): Spatially Nonstationary Relationships Between Urban Residential Land Price and Impact Factors in Wuhan City, China. - Appl. Geogr. 68(68): 48-56.

[12] Huang, M., Xing, X., Wang, P. (2006): Comparison between Three Different Methods of Retrieving Surface Temperature from Landsat TM thermal Infrared Band. - Arid Land Geography 29(1): 132-137.

[13] Jiang, M., Zeng, S., Zeng, J. (2015): Urban Expansion of Tianjin and the Micro Climate Characteristics Evolution-Based on the Urban Thermal Environment Perspective. Journal of Arid Land Resources and Environment 29(9): 159-164.

[14] Liao, F. H., Wei, Y. D. (2014): Modeling Determinants of Urban Growth in Dongguan, China: A Spatial Logistic Approach. - Stoch. Environ. Res. Risk Assess. 28: 801-816.

[15] Mihai, B., Nistor, C., Simion, G. (2015): Post-Socialist Urban Growth of Bucharest, Romania: A Change Detection Analysis on LANDSAT Imagery (1984-2010). - Acta Geogr. Slov. 55(2): 223-234.

[16] Qin, Z., Li, W., Xu, B., Chen, Z., Liu, J. (2004): The Estimation of Land Surface Emissivity for Landsat TM6. - Remote Sensing for Land \& Resources 17(3): 28-42.

[17] Rogan, J., Ziemer, M., Martin, D., Ratick, S., Cuba, N., DeLauer, V. (2013): The Impact of Tree Cover Loss on Land Surface Temperature: A Case Study of Central Massachusetts Using Landsat Thematic Mapper Thermal Data. - Appl. Geogr. 45: 49-57.

[18] Shi, B., Wang, X., Zhao, D. (2017): Numerical Simulation of the Effects of Sky-view Factor on Thermal Environment in Urban Residential Districts. - Chinese Journal of Applied Mechanics 34(7): 1181-1186.

[19] Wang, P., Zhang, J., Lv, R. (2014): Urban Thermal Environment Pattern with Spatial Autocorrelation in Lanzhou. - Chinese Journal of Ecology 33(4): 1089-1095.

[20] Yao, Z., Wei, H., Liu, H., Li, Z. (2013): Statistical Vehicle Specific Power Profiling for Urban Freeways. - Procedia-Social and Behavioral Sciences 96: 2927-2938.

[21] Yin, C., Shi, Y., Wang, H., Wu, J. (2015): Impact of Urban Landscape Form on Themal Environment at Multi-Spatial Levels. - Resource and Environment in the Yangtze Basin 24(1): 97-105.

[22] Zhang, W., Jiang, J., Zhu, Y. (2015): Spatial-temporal Evolution of Urban Thermal Environment Based on Spatial Statistical Features. - Chinese Journal of Applied Ecology 26(6): 1840-1846.

[23] Zhen, G., Hu, Y., Li, H. (2016): Study of Temporal and Spatial Distribution of Thermal Environment in Wuhan City. - Science of Survey and Mapping 41(6): 84-86.

[24] Zheng, Z. (2013): Statistical analysis of the effects of urbanization on haze days in Beijing area. - Ecology and Environmental Sciences 21(8): 1381-1385. 